\title{
"H" is not for hydroxychloroquine- "H" is for heparin: lack of efficacy of hydroxychloroquine and the role of heparin in COVID-19-preliminary data of a prospective and interventional study from Brazil
}

\author{
Renata de Oliveira Costa ${ }^{1,2}$, Joyce Santos Nascimento ${ }^{2}$, Cadiele Oliana Reichert ${ }^{3}$, \\ Adriana Pedroso Augusto da Costa ${ }^{2}$, Maria Aparecida Pedrosa dos Santos ${ }^{1,2}$, Alberto Macedo Soares ${ }^{1,2}$, \\ Carlos Eduardo Mendonça Tomé ${ }^{1,2}$, Ricardo Leite Hayden², Cassiano Waldanski dos Santos², \\ Bruno Barreiro², Amer Abdul Basset El-Khatib² ${ }^{2}$ Luís Alberto de Pádua Covas Lage ${ }^{4,5^{*}}$, Juliana Pereira ${ }^{4,5}$ and \\ Mônica Mazzurana Benetti
}

\begin{abstract}
Background: COVID-19 pandemic is the major public health problem in the world actually. It's associated with high morbidity and mortality. To date, no therapeutic measure has a curative potential. Hydroxychloroquine (HCQ) is a drug with immunomodulatory properties that has demonstrated antiviral efficacy in in vitro experiments, with conflicting results in in vivo studies.

Methods: A single-center, prospective and interventional study, that evaluates the impact on mortality of the HCQ use in 154 patients hospitalized with COVID-19 in a Brazilian public hospital. The study also aims to determine prognostic factors that predict mortality, ICU admission and endotracheal intubation in this population.

Results: 154 patients diagnosed with COVID-19 confirmed by RT-PCR and hospitalized were included. There was a male predominance $(87 / 154,56.5 \%)$, median age 60 years and $88 \%(136 / 154)$ had comorbidities. Among these, $76 \%$ $(117 / 154)$ were admitted to the ICU and 29.2\% (45/154) experienced EOT. The OMR was 51.3\% (79/154). There was no difference in mortality between patients treated with HCQ $(N=95)$ and non-HCQ $(N=59)(44.1 \% \times 55.8 \%, p=0.758)$. In univariate analysis, age $\geq 60$ years (HR 3.62, $p<0.001$ ), need for mechanical ventilation (HR 2.17, $p=0.001), \geq 2$ comorbidities (HR 1.83, $p=0.049$ ), SAH (HR: 1.56, $p=0.054$ ) were predictors of mortality, as well as no use of prophylactic or therapeutic heparin (HR 3.60, $p=0.02$ ). Multivariate analysis identified admission to the ICU (HR 8.98, $p=0.002)$ and advanced age (HR 3.37, $p<0.01)$ as independent predictors of mortality, although, use of heparin ( $H R$ $0.25, p=0.001$ ) was independently associated with a favorable outcome.
\end{abstract}

\footnotetext{
*Correspondence: luis.lage@hc.fm.usp.br; luisalberto_lage@yahoo.com.br

${ }^{4}$ Department of Hematology, Hemotherapy \& Cell Therapy, University

of São Paulo (USP), Av. Dr. Enéas de Carvalho Aguiar, 155 - 1st. Floor.

Room 61, SP, São Paulo, Brazil

Full list of author information is available at the end of the article
}

(c) The Author(s) 2022. Open Access This article is licensed under a Creative Commons Attribution 4.0 International License, which permits use, sharing, adaptation, distribution and reproduction in any medium or format, as long as you give appropriate credit to the original author(s) and the source, provide a link to the Creative Commons licence, and indicate if changes were made. The images or other third party material in this article are included in the article's Creative Commons licence, unless indicated otherwise in a credit line to the material. If material is not included in the article's Creative Commons licence and your intended use is not permitted by statutory regulation or exceeds the permitted use, you will need to obtain permission directly from the copyright holder. To view a copy of this licence, visit http://creativecommons.org/licenses/by/4.0/. The Creative Commons Public Domain Dedication waiver (http://creativeco mmons.org/publicdomain/zero/1.0/) applies to the data made available in this article, unless otherwise stated in a credit line to the data. 
Conclusion: This study confirmed the absence of a benefit associated with the use of HCQ in Brazilian patients hospitalized with COVID-19. However, prophylactic or therapeutic heparin was an independent predictor for reducing mortality in this population.

Keywords: COVID-19, Heparin, Hydroxychloroquine, Prognostic factors, Outcomes

\section{Introduction}

More than one year ago, in December 2019, an outbreak caused a respiratory illness in Wuhan, China, caused by a novel coronavirus ( $\mathrm{nCov}$ ) and later named Coronavirus disease 2019 (COVID-19) [1]. The severe form of this disease, characterized by hypoxemic respiratory failure, was called Severe Acute Respiratory Syndrome (SARS-Cov-2) [1]. Although we have made some progress on its therapy management, the disease has unfortunately resulted in 152.406.001 confirmed cases and 3.196.275 deaths globally till now [2]'Despite the fact that many potential vaccines were developed, there are immense logistical challenges in distributing to all vulnerable people, especially in developing countries. So, with the spread of COVID-19 moving on and a "third" wave emerging, there are no option out of caring for hospitalized patients with COVID-19.

Hydroxychloroquine (HCQ), an aminoquinolone used on the treatment of autoimmune diseases and malaria showed, on a small non-randomized trial, in the beginning of the COVID-19 pandemic, high efficacy with virologic cure when associated with azithromycin (AZTH) [3].

In Brazil, since March 2020, the Ministry of Health made available both Hydroxychloroquine and azithromycin for severe cases, at the discretion of the treating physician [4]. On May, both drugs had the recommendation expanded for mild cases [5]. With the first COVID-19 case recorded in Brazil located in São Paulo, considering the threat of the COVID-19 pandemic and with no randomized controlled trials available on timeframe, we performed an unicentric, prospective, interventional and consecutive non-randomized study to assess whether HCQ alone or in combination with azithromycin, would impact on mortality outcomes in hospitalized patients with documented pneumonia for COVID-19 on Public Health System in Brazil.

\section{Materials and methods Study design and patients}

This is a prospective, non-randomized and unicentric cohort study conducted at Guilherme Álvaro Hospital (HGA) in Santos, São Paulo, Brazil. It is one of the largest hospitals in Metropolitan Region of Baixada Santista, $100 \%$ dedicated to Public Health System. Since March 2020, we have adapted isolation cohorts into COVID-19 dedicated beds as needs during the pandemic. The protocol was approved by the Committee for Ethics in Research (CEP number 3448). Furthermore, the study was registered at the National Research Ethics Commission (CONEP number: 30538920.9.0000.0008).

The study protocol was described for participants and written informed consents were obtained from all patients or their legal representatives. We included patients who were at least 18 years-old admitted to hospital with confirmed COVID-19 and radiographically documented pneumonia. An electrocardiogram was made at baseline, and as clinically indicated. Exclusion criteria was known hypersensitivity to $\mathrm{HCQ}$, retinopathy, pregnancy or, in the physician's view, any contraindication to the drug. Patients with exclusion criteria were used as control group and compared to those recruited to receive HCQ. For all patients a RT-PCR of the E, N and RdRP genes assay of nasal specimens, throat-swab specimens, or tracheal aspirate were used to confirm SARS-Cov-2 infection. Negative RT-PCR patients were submitted to a second RT-PCR test. Negative patients from both tests were excluded from the study, as well as patients only positive for serologic external results.

\section{Treatment regimens}

After written informed consent provided by patients or by their legal representatives, eligible patients were recruited to HCQ group (alone or in combination with azithromycin) or to standard of care. Patients in the HCQ group received $400 \mathrm{mg}$ hydroxychloroquine twice daily on first day followed by $400 \mathrm{mg}$ for 4 days orally or via nasogastric tube in case of orotracheal intubation. Azithromycin $500 \mathrm{mg}$ by oral, nasogastric or intravenous route for 5 days was allowed. The standard of care for COVID-19 was at the discretion of the treating physician. The use of corticosteroids and the antiviral oseltamivir was allowed, as well as other supportive care such as routine use of deep vein thrombosis prophylaxis and systemic antibiotics if bacterial infection coexisted. Specific protocols for the ventilatory management of respiratory failure and for sedation management throughout ICU stay was performed according to the hospital protocols.

\section{Outcomes}

The primary end point was efficacy of hydroxychloroquine on death outcome. Secondary endpoints included 
analyses of any clinical or interventional parameters as predictive risk factors for death and lethality. All patients and their parameters were monitored until discharge.

\section{Laboratory and radiographic analysis}

Routine blood examinations included basic metabolic panel, liver function, complete blood count and differential, ferritin, magnesium, C-reactive protein (CRP), lactate dehydrogenase $(\mathrm{LDH})$, troponin and $\mathrm{D}$-dimer. Baseline chest radiograph and/or computerized tomography $(\mathrm{CT})$ were done at admission and furthermore as clinically determined by health care practitioners considering the individual evolution of each case. Laboratory assays for confirmation of SARS-Cov- 2 were done as described above.

\section{Statistical analysis}

Data are presented in accordance with the variables evaluated. Categorical variables are presented in absolute $(\mathrm{N})$ and relative (percentage) numbers. Numerical variables are presented as mean and standard deviation (SD); as well as median, $25 \%$ percentile and $75 \%$ percentile, and minimum and maximum values. Overall Survival (OS) analysis was performed using the Kaplan-Meier (KM) method, and the Log-Rank (Mantel-Cox) test was used for comparisons between groups. Predictor analysis for the outcome was performed using Cox's semi-parametric univariate and multivariate regression or proportional hazards model, in which a value of $\mathrm{p} \leq 0.15$ was accepted for inclusion of the predictor in the final model. The order of inclusion of predictive factors in the multivariate analysis was performed using the lowest $\mathrm{p}$ value. The results are presented in Hazard Ratio (HR) and 95\% Confidence Interval (95\% CI). All analyzes were performed using the SPSS statistical software (IBM SPSS version 22.0) for Windows. A value of $\mathrm{p} \leq 0.05$ was assigned as significant.

\section{Results}

\section{Clinical characteristics of the patients with COVID-19 infection}

From March 28 to July 31, 2020, a total of 326 patients were hospitalized with suspected or external confirmed COVID-19 at our center. Of these 154 (47.2\%) patients entered in this analysis. In this study, 172 (53.7\%) patients were excluded because of negative internal RTPCR for SARS-Cov-2, pregnancy or age $<18$ years. A total of 95/154 (61.7\%) received HCQ, and follow-up was completed on August 15, 2020. Baseline characteristics of patients are shown in Table 1 . There was predominance of male gender (56.5\%) and a median age of 60 years (range 21-90). Most patients, 136/154 (88.3\%) had comorbidities, and the majority 51/154 (33.1\%) had
Table 1 Clinical characteristics, support and treatment of 154 patients with COVID-19 infection

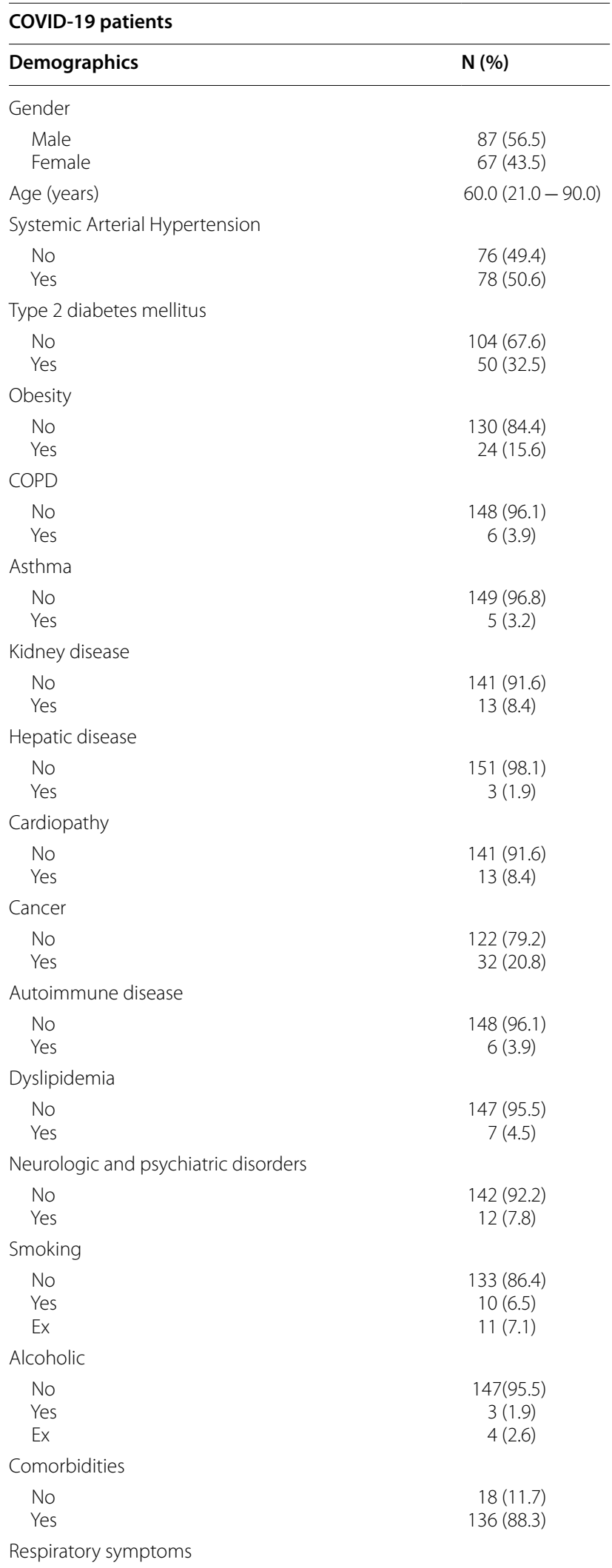


Table 1 (continued)

\begin{tabular}{|c|c|}
\hline \multicolumn{2}{|c|}{ COVID-19 patients } \\
\hline Demographics & N (\%) \\
\hline $\begin{array}{l}\text { No } \\
\text { Yes }\end{array}$ & $\begin{array}{r}26(16.9) \\
128(83.1)\end{array}$ \\
\hline \multicolumn{2}{|l|}{ ICU admission } \\
\hline $\begin{array}{l}\text { No } \\
\text { Yes }\end{array}$ & $\begin{array}{r}37(24.0) \\
117(76.0)\end{array}$ \\
\hline \multicolumn{2}{|l|}{ Oseltamivir } \\
\hline $\begin{array}{l}\text { No } \\
\text { Yes }\end{array}$ & $\begin{array}{r}36(23.4) \\
118(76.6)\end{array}$ \\
\hline \multicolumn{2}{|l|}{ Azithromycin } \\
\hline $\begin{array}{l}\text { No } \\
\text { Yes }\end{array}$ & $\begin{array}{r}24(15.6) \\
130(84.4)\end{array}$ \\
\hline \multicolumn{2}{|c|}{ Hydroxychloroquine } \\
\hline $\begin{array}{l}\text { No } \\
\text { Yes }\end{array}$ & $\begin{array}{l}59(38.3) \\
95(61.7)\end{array}$ \\
\hline \multicolumn{2}{|l|}{ Corticosteroids } \\
\hline $\begin{array}{l}\text { No } \\
\text { Yes }\end{array}$ & $\begin{array}{r}39(25.3) \\
115(74.7)\end{array}$ \\
\hline \multicolumn{2}{|l|}{ Heparin } \\
\hline $\begin{array}{l}\text { No } \\
\text { Yes }\end{array}$ & $\begin{array}{c}8(5.2) \\
146(94.8)\end{array}$ \\
\hline \multicolumn{2}{|l|}{ DVT } \\
\hline $\begin{array}{l}\text { No } \\
\text { Yes }\end{array}$ & $\begin{array}{c}152(98.7) \\
2(1.3)\end{array}$ \\
\hline \multicolumn{2}{|c|}{ Endotracheal Intubation } \\
\hline $\begin{array}{l}\text { No } \\
\text { Yes }\end{array}$ & $\begin{array}{r}109(70.8) \\
45(29.2)\end{array}$ \\
\hline \multicolumn{2}{|c|}{ Pulmonary involvement $>50 \%$} \\
\hline $\begin{array}{l}\text { No } \\
\text { Yes } \\
\text { No CT }\end{array}$ & $\begin{array}{l}58(37.7) \\
59(38.3) \\
37(24.0)\end{array}$ \\
\hline
\end{tabular}

COPD Chronic obstructive pulmonary disease, ICU Intensive care unit, DVT Deep vein thrombosis, $N$ number of individuals, $\%$ percentage

at least 2 comorbidities. Systemic arterial hypertension (SAH) was the most frequent comorbidity $78 / 154$ (50.6\%), followed by diabetes mellitus 50/154 (32.5\%), cancer 32/154 (20.8\%) and obesity 24/154 (15.2\%). Dyspnea, cough and fever were the most common symptoms, with one of these occurring in 128/154 (83.1\%). In 17/154 (11\%) patients, atypical findings such as nausea, vomiting and diarrhea were present and 9/154 (5.8\%) patients were asymptomatic or had no symptoms registered in medical records.

Among all hospitalized patients, 117/154 (76\%) were admitted on Intensive Care Unit (ICU) and 45/154 (29.2\%) had endotracheal intubation (EOT) requirement (Table 1). Among patients submitted to lung computerized tomography, 59/117 (50.4\%) had more than 50\% involvement of the lungs. HCQ was given for $95 / 154$ (61.7\%) patients, and azithromycin for 130/154 (84.4\%). In 118/154 (76.6\%) patients, the antiviral oseltamivir was administrated and 115/154 (74.7\%) received corticosteroids during the hyper-inflammation phase. Deep venous thromboembolism (DVT) was confirmed in 2/154 (1.3\%) patients and heparin was used in 146/154 (94.8\%) patients.

\section{Outcomes}

In this cohort, the total death rate was $51.3 \%$ (79/154) and the median of overall survival (OS) from the onset of symptoms until the discharge from the hospital was 21 days (95\% CI: 17.047 - 24.953) (Fig. 1).

The primary end point of outcome, efficacy of HCQ on death is shown in Fig. 2. There were not significant differences of mortality among patients treated with HCQ 95/154 (61.7\%) and those that did not received this drug $59 / 154$ (38.3\%). The mortality rate was $44.1 \%(26 / 59)$ in non-HCQ group and 55.8\% (53/95) in HCQ group (median OS 22.0 days, [95\% CI: 18.0-25.9] for HCQ group, and median OS 18.0 days, [95\% CI: 16.4-19.5] for non-HCQ group, $\mathrm{p}=0.758$ ).

Table 2 shows a comparison of clinical and therapeutic characteristics between patients in the HCQ and nonHCQ groups included in our analysis.

\section{Clinical factors associated with poor prognosis in patients with COVID-19}

In univariate analysis, age $\geq 60$ years was predictive for death (HR: 3.628; 95\% CI: $2.208-5.960 ; P<0.001$ ) (Table 3). Gender, deep vein thrombosis and pulmonary involvement $>50 \%$ were not predictive for death. Systemic arterial hypertension presented a tendency for increment of death (HR: 1.564; 95\% CI: 0.992- 2.466; $P=0.054)$. Single comorbidities as cardiovascular disease, obesity, chronic kidney disease (CKD), chronic obstructive pulmonary disease (COPD), asthma, DM, liver disease, cancer and smoking were not predictive for death. However, the presence of $\geq 2$ comorbidities were statistically significant predictive of death (HR: 1.832; 95\% CI: $1.003-3.346 ; P=0.049$ ). Gastrointestinal symptoms such as nausea, vomiting and diarrhea were not predictive of death (HR: 2.217 ; 95\% CI: $0.893-5.507 ; P=0.086$ ), as well oseltamivir, $\mathrm{HCQ}$, corticosteroids and azithromycin use. Heparin showed significant impact on survival, since patients who did not take heparin had a risk of death 3.6 times greater than those who used prophylactic or therapeutic heparin (HR: 3.606; 95\% CI: $1.632-7.966$; $P=0.002)$. Patients with necessity of mechanical ventilation also presented higher risk of death (HR: 2.176; 95\% CI: $1.386-3.419 ; P=0.001)$. Hospitalization at ICU (HR: 8.194; 95\% CI: $2.001-33.553 ; P=0.003)$ were also associated with high risk of death.

In addition, the multivariate analysis showed four predictors factors of death in COVID-19 patients 


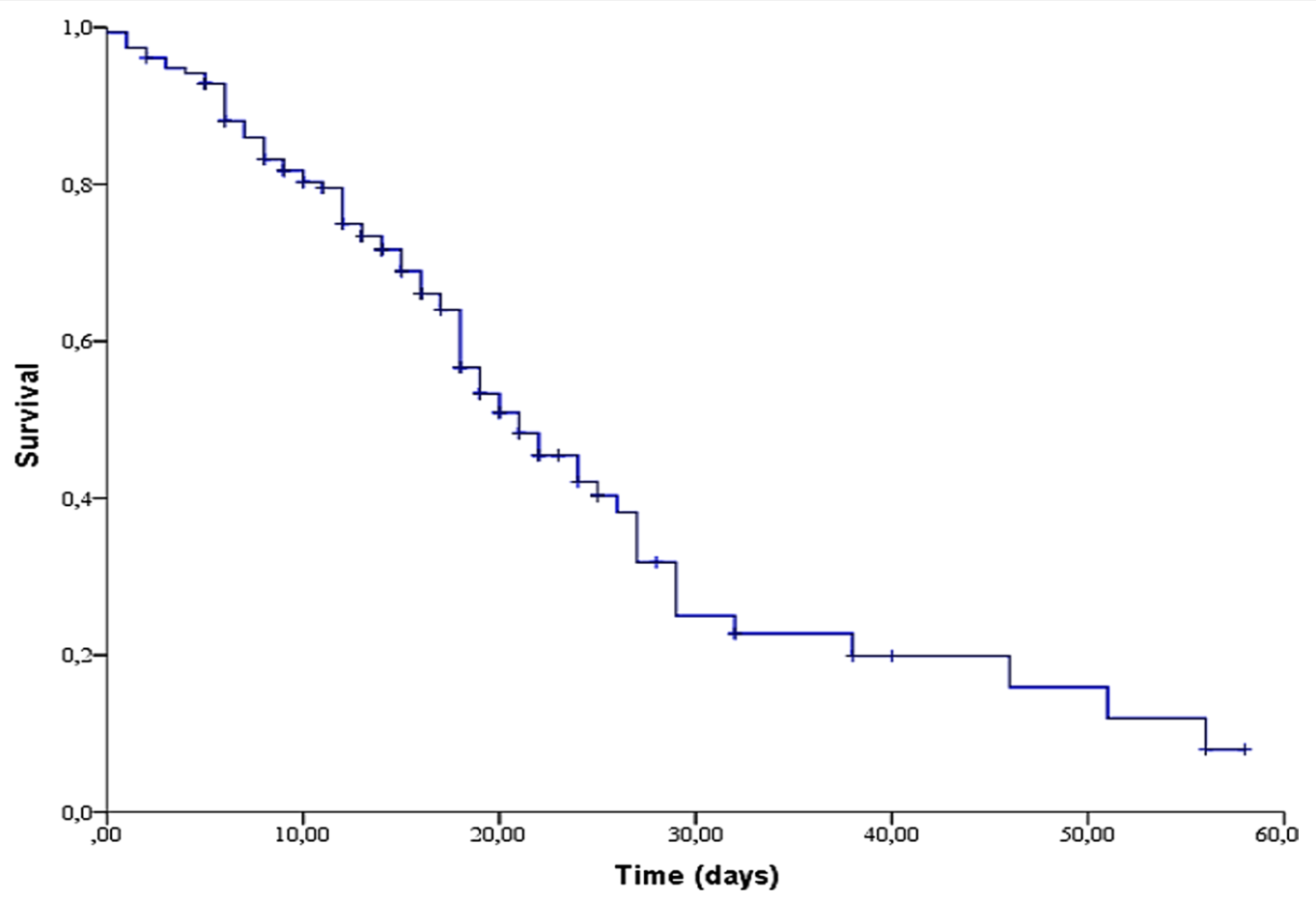

Fig. 1 Overall survival of the 154 in-patients with COVID-19
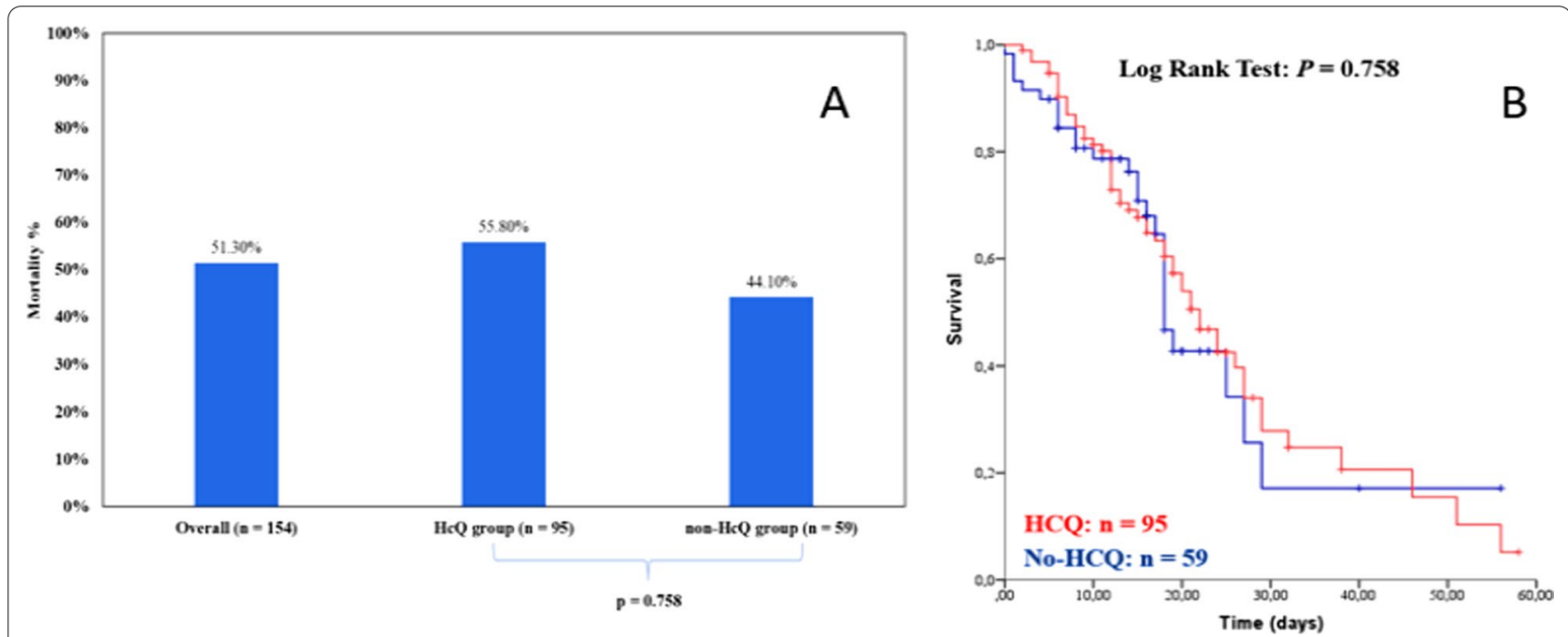

Fig. 2 A-Mortality rates in COVID-19 hospitalized patients, groups HCQ and non-HCQ; B - Overall survival curve in the groups HCQ and non-HCQ. Comparison between groups by Log Rank Test $(p=0.758)$

(Table 4). The ICU admission (HR: 8.980; 95\% CI: 2.168-37.190; $\mathrm{P}=0.002$ ) was the main factor, followed by age above 60 years (HR: 3.475 ; $95 \%$ CI: $2.015-5.666$; $P<0.001)$. In opposition, heparin use was protector of death (HR: $0.254 ; 95 \%$ CI: $0.113-0.569 ; P=0.001$ ).
There was a tendency of protection against death for GI symptoms (HR: 0.404; 95\% CI: 0.160-1.023; $\mathrm{P}=0.056$ ). Age above 60 years was also predictive for ICU admission (HR: 1.956; 95\% CI: 1.328-2.882; $P=0.001$ ) (Table 4). 
Table 2 Comparison of clinical parameters between the non-HCQ and HCQ groups

\begin{tabular}{|c|c|c|c|}
\hline \multicolumn{4}{|l|}{ COVID-19 patients $(\mathrm{N}=154)$} \\
\hline Demographics & Non-HCQ N = 59 (\%) & $\mathrm{HCQ} N=95(\%)$ & $p$ value \\
\hline \multicolumn{4}{|l|}{ Gender } \\
\hline Male & $36(61.0)$ & $51(53.7)$ & 0.372 \\
\hline Female & $26(39.0)$ & $44(46.3)$ & \\
\hline Age (years) & $61(22-89)$ & $59(21-90)$ & 0.254 \\
\hline Systemic Arterial Hypertension & $30(50.8)$ & $48(50.5)$ & 0.969 \\
\hline Type 2 diabetes mellitus & $19(32.2)$ & $31(32.6)$ & 0.956 \\
\hline Obesity & $7(11.9)$ & $17(17.9)$ & 0.316 \\
\hline COPD & $2(3.4)$ & $4(4.2)$ & 0.798 \\
\hline Asthma & 0 & $5(5.3)$ & 0.073 \\
\hline Kidney disease & $6(10.2)$ & $7(7.4)$ & 0.543 \\
\hline Hepatic disease & 0 & $3(3.2)$ & 0.168 \\
\hline Cardiopathy & $6(10.2)$ & $7(7.4)$ & 0.543 \\
\hline Cancer & $20(33.9)$ & $12(12.6)$ & 0.002 \\
\hline Autoimmune disease & $2(3.4)$ & $4(4.2)$ & 0.798 \\
\hline Dyslipidemia & $4(6.8)$ & $3(3.2)$ & 0.294 \\
\hline Neuro and psychiatric disorders & $7(11.9)$ & $5(5.3)$ & 0.137 \\
\hline \multicolumn{4}{|l|}{ Smoking } \\
\hline $\begin{array}{l}\text { Yes } \\
\text { Ex }\end{array}$ & $3(5.1)$ & $7(7.4)$ & 0.183 \\
\hline \multicolumn{4}{|l|}{ Alcoholic } \\
\hline $\begin{array}{l}\text { Yes } \\
\text { Ex }\end{array}$ & $\begin{array}{l}1(1.7) \\
4(6.8)\end{array}$ & $\begin{array}{l}2(2.1) \\
0\end{array}$ & 0.036 \\
\hline Comorbidities & $55(93.2)$ & $81(85.3)$ & 0.135 \\
\hline Comorbidities $\geq 2$ & $43(78.2)$ & $57(70.4)$ & 0.311 \\
\hline Pulmonary involvement $>50 \%$ & $20(42.6)$ & $39(55.7)$ & 0.163 \\
\hline Pneumonia & $55(93.2)$ & $94(98.9)$ & 0.071 \\
\hline ICU admission & $41(69.5)$ & $76(80.0)$ & 0.138 \\
\hline Oseltamivir & $33(55.9)$ & $85(89.5)$ & $<0.001$ \\
\hline Azithromycin & $39(66.1)$ & $91(95.8)$ & $<0.001$ \\
\hline Corticosteroids & $40(67.8)$ & $75(78.9)$ & 0.122 \\
\hline Heparin & $52(88.1)$ & $94(98.9)$ & 0.005 \\
\hline Endotracheal Intubation & $12(20.3)$ & $33(34.7)$ & 0.056 \\
\hline DVT & $1(1.7)$ & $1(1.1)$ & 1.000 \\
\hline
\end{tabular}

Comparison of categorical variables using the Chi-square test between non-HCQ and HCQ groups. ICU Intensive care unit, DVT Deep vein thrombosis, N number of individuals, $\%$ percentage

\section{Discussion}

In this unicentric, prospective, interventional and nonrandomized study, conducted in a public tertiary Hospital in Brazil, treatment with hydroxychloroquine had no impact on mortality outcomes in hospitalized patients with documented pneumonia for COVID-19. When we compared the mortality rate among patients treated or not treated with HCQ we did not find any significant difference ( 55.8 vs $44.1 \%$; $P=0.758$ ).

At the beginning of a frightening and unique pandemic moment, with no randomized controlled trial available, with local recommendations in favor of the use of the
HCQ, our study was carried out based on ethical concerns and in order to answer the question of its benefit and guide us towards of good quality for clinical decisions. Also, the rationale and decision for prescribing this drug was based on the preliminary study in France, which showed virological cure in patients who received HCQ combined with azithromycin, the confidence and experience of Brazilians physicians with the use of HCQ for decades on the treatment of malaria, autoimmune disorders and prompt availability of the drug [2,3].

With limitations regarding an unicentric, small number of cases and a more serious manifestation of SARS-Cov-2 
Table 3 Clinical risk factors associated with the death of patients with COVID-19

\begin{tabular}{|c|c|c|c|c|}
\hline Clinical features & $\beta$-value & Hazard ratio & Confidence interval (95\%) & $p$ value \\
\hline Gender & 0.028 & 1.028 & $0.656-1.612$ & 0.904 \\
\hline Age $\geq 60$ years & 1.289 & 3.628 & $2.208-5.960$ & $<0.001$ \\
\hline Mechanical ventilation & 0.778 & 2.176 & $1.386-3.419$ & 0.001 \\
\hline Comorbidities & 0.101 & 1.106 & $0.507-2.414$ & 0.801 \\
\hline Comorbidities $(\geq 2)$ & 0.605 & 1.832 & $1.003-3.346$ & 0.049 \\
\hline Heparin (no use) & 1.282 & 3.606 & $1.632-7.966$ & 0.002 \\
\hline Deep Venous thromboembolism & 0.015 & 1.015 & $0.141-7.328$ & 0.988 \\
\hline Pulmonary involvement > 50\% & 0.263 & 1.301 & $0.704-2.404$ & 0.400 \\
\hline Hydroxychloroquine use & 0.073 & 1.076 & $0.669-1.730$ & 0.762 \\
\hline Asymptomatic & -0.427 & 0.652 & $0.262-1.623$ & 0.358 \\
\hline Gastrointestinal symptoms & 0.796 & 2.217 & $0.893-5.507$ & 0.086 \\
\hline Cardiovascular disease & 0.563 & 1.757 & $0.871-3.544$ & 0.116 \\
\hline Liver Disease & 1.143 & 3.137 & $0.755-13.042$ & 0.116 \\
\hline Chronic kidney disease & 0.473 & 1.605 & $0.822-3.135$ & 0.166 \\
\hline Asthma & -3.058 & 0.047 & $0.001-19.973$ & 0.322 \\
\hline COPD & 0.349 & 1.418 & $0.444-4.530$ & 0.556 \\
\hline Smoking & 0.458 & 1.581 & $0.577-4.335$ & 0.373 \\
\hline Diabetes & -0.011 & 0.989 & $0.627-1.560$ & 0.962 \\
\hline Obesity & 0.061 & 1.063 & $0.618-1.826$ & 0.826 \\
\hline Systemic arterial hypertension & 0.447 & 1.564 & $0.992-2.466$ & 0.054 \\
\hline Cancer & 0.367 & 1.443 & $0.848-2.458$ & 0.177 \\
\hline Oseltamivir & 0.280 & 1.323 & $0.767-2.283$ & 0.314 \\
\hline Corticosteroids & -0.268 & 0.765 & $0.399-1.465$ & 0.419 \\
\hline Azithromycin & 0.125 & 1.133 & $0.596-2.156$ & 0.703 \\
\hline Intensive Care Unit (ICU) & 2.103 & 8.194 & $2.001-33.553$ & 0.003 \\
\hline
\end{tabular}

Univariate analysis for death in patients with COVID-19 by Cox Regression or Proportional Risk Model

Table 4 Association between clinical factors related to increased risk of death and increased risk of ICU admission in patients with COVID-19

\begin{tabular}{|c|c|c|c|c|}
\hline Clinical features associated with death & $\beta$ value & Hazard ratio & 95\% Confidence interval & $P$ value \\
\hline Age $\geq 61$ years & 1.218 & 3.379 & $2.015-5.666$ & $<0.001$ \\
\hline Heparin (use) & -1.372 & 0.254 & $0.113-0.569$ & 0.001 \\
\hline Intensive Care Unit (ICU) & 2.195 & 8.980 & $2.168-37.190$ & 0.002 \\
\hline Gastrointestinal symptoms & -0.905 & 0.404 & $0.160-1.023$ & 0.056 \\
\hline $\begin{array}{l}\text { Clinical features associated with ICU } \\
\text { admission }\end{array}$ & $\beta$ value & Hazard ratio & 95\% Confidence interval & $P$ value \\
\hline Age $\geq 61$ years & 0.599 & 1.820 & $1.245-2.660$ & 0.002 \\
\hline Heparin (use) & -0.776 & 0.460 & $0.200-1.059$ & 0.068 \\
\hline Neurological diseases & 0.777 & 2.029 & $0.965-4.263$ & 0.062 \\
\hline Oseltamivir & -0.363 & 0.695 & $0.446-1.085$ & 0.110 \\
\hline
\end{tabular}

Multivariate analysis for risk of death and for ICU admission in COVID-19 patients by Cox Regression or Proportional Risk Model

infection in our cohort, our finding is consistent with a more robust data showing no benefit of HCQ in adults hospitalized with COVID-19 [5, 6]. Although in our study the cardiac toxicity effect of HCQ could not be unreliable assessed because most patients were using azithromycin and synergistic toxic effects are well known, the 5 days use of both drugs were done inpatient, so that monitoring and adherence were well controlled [7]. Also, another 
limitation of our study was the lack of a panel flu-test. Although part of our study occurred during influenza season and oseltamivir was administered for $76.6 \%$ of the patients, clinical symptoms can overlap with the COVID19 [8]. Yet, RT-PCR for SARS-Cov-2 was positive in all cohort.

In our cohort, $51.3 \%(79 / 154)$ evolved to death during hospitalization in a median time of 21 days ( $95 \% \mathrm{CI}$, 17.047-24.953) from the onset of symptoms. In agreement with others reports, the most frequent symptoms of our patients with COVID-19 were dyspnea, cough and fever, found in 128/154 (83.1\%) patients $[9,10]$. Likewise, unspecific gastrointestinal symptoms of nausea, vomiting and diarrhea were seen in 17/154 (11\%) patients. As expected, respiratory symptoms were present in the majority of patients.

In comparison to others studies, our casuistic comprehended more vulnerable patients with higher risk to develop complications and death by COVID-19. In our cohort, the median age of patients were 60 years and 136/154 (88.3\%) of them presented comorbidities, being systemic arterial hypertension the most frequent, observed in $50.6 \%$ of them (78/154). Malignant neoplasms were present in $20.8 \%$ (32/154) of patients. Therefore, these worse clinical aspects of our casuistic may justify our higher mortality in comparison with other studies. Fei Zhou et cols. reported that in a total of 191 inpatients in a Hospital in Wuhan, China, the epicenter of the beginning of the SARS-Cov- 2 pandemic, 137 were discharged and $54(28.3 \%)$ died [11]. In this report 91 $(48 \%)$ of patients presented comorbidities. In multivariate analysis, they showed, like us, that older age was associated with higher risk of in-hospital death. [11]. Wu Z et al., showed that $49 \%$ of inpatients with severe COVID19 had comorbidities [12].

The univariate analysis showed that age equal or higher than 60 years, mechanical ventilation necessity, presence of at least two comorbidities, no heparin use and SAH were predictive of death. However, in multivariate analysis age equal or higher than 60 years and EOT necessity remained as independent factors for mortality. Interestingly, heparin use was beneficial and related to lower mortality. Age equal or higher than 60 years was also predictive for ICU admission in multivariate analysis. The ICU care was required for $76.9 \%(117 / 152)$ patients and $67.5 \%(79-117)$ of them evolved to death. During this study, the ICU beds were widely available and all patients were immediately admitted in this unit when necessary. In the beginning of the pandemic it was verified that risk of death increased with older age. In a Chinese series, the mortality was $0.5 \%$ in patients younger than 50 years, $2 \%$ (50-59 years), 4\% (60-69 years), 8\% (70-79 years) and $16 \%$ (> 80 years) [13]. The authors reported $67 \%$ of mortality in patients over 80 years, $20 \%$ between 70 and 79 years and $8 \%$ between 60 and 69 years [13]. However, the comparison of mortality among many countries is not all reliable, because of different medical resources.

Despite of the scientific advances acquired last year, till now some parts of the world are astonishing and in some words lost with this disease. In fact, in the beginning old people were dragged into this tourbillion named SARSCov-2 pandemic and although our cohort also found age an important and independent factor for mortality in patients with COVID-19 hospitalized, now we are faced with new mutations, younger patients requiring medical assistance and dealing with the hospitalized patient is an everyday practice for many physicians. Unfortunately, in Brazil, apart from initial recommendations regarding HCQ use, no former protocol regarding the best of care for inpatient COVID-19 was made available by the Ministry of Health until April 2021.

Aging is associated with decline of immune function, $\mathrm{T}$ and $B$ lymphocytes dysfunction [14-16] as well as lower level of interferon type 1 [17-19]. On the other hand, old people carry more comorbidities and consequently higher probability to develop more complication in the setting of infection. Aging is also associated with a higher inflammatory steady-state caused by a higher production of cytokines [20]. These conditions certainly have contributed to the clinical severity and higher mortality associated with COVID-19 in older people [20].

Another important aspect of the COVID-19 is that an explosion of thrombi-inflammation seen in the hyper inflammation phase results in micro-thrombosis of lung vasculature and in a severe interstitial pneumonia characterized by severe hypoxemia with acute respiratory insufficiency, with necessity of high concentration of oxygen supplying and, in more severe patients, invasive ventilatory support. Less frequently, patients can also develop acute renal failure increasing the gravity of the disease [21].

Because of this physiopathology and the high rate of thromboembolic complication in patients with COVID19 [22], prophylactic administration of low-molecular weight heparin (LMWH) for hospitalized COVID-19 patients is recommended [23]. However, Paranjpe et al. showed that systemic anticoagulation has been associated with COVID-19 benefit only in subgroup of patients with EOT [24]. Unexpectedly, at the time of this study was conducted, in the beginning of the pandemic in Brazil, we found that heparin was and independent protector factor against mortality in multivariate analysis in our casuistic. Beyond it anticoagulation action, heparin also have others functions, like inhibition of heparase enzyme and linked to endothelial leakage. It also capable of neutralizing chemokines, cytokines and the cell 
influx of extracellular cytotoxic histones. Moreover, heparin prevents the viral cellular uptake and interfere with leukocyte trafficking [23, 25], directly interfering with pathophysiological mechanisms associated with viral infection progression and endothelial damage.

Some limitations should be highlighted in our study. Although evaluation by computed tomography is considered the gold standard for assessing pulmonary parenchyma involvement by COVID-19 and quantifying its extension, only $76 \%$ of our patients $(117 / 154)$ were evaluated using this imaging technique. Most of the remaining cases had an image evaluation done by chest radiography, because these are severe cases, including patients on mechanical ventilation, whose transport to the imaging sector offered logistical difficulties and imminent risk to the patient's life during transport. However, these cases showed evident involvement of the pulmonary parenchyma with more than $50 \%$ involvement of this organ on the chest X-ray.

Individuals with COVID-19 included in the HCQ and non-HCQ groups have comparable clinical characteristics as summarized in Table 3, with the exception of a higher percentage of neoplasia and alcoholism in the non-HCQ group. Regarding therapeutic management variables, the non-HCQ group had a lower percentage of exposure to oseltamivir, azithromycin and heparin, with a statistically significant difference. In multivariate analysis, therapy with oseltamivir and azithromycin had no impact on risk of death.

Unlike what was demonstrated by the RECOVERY study, where exposure to low doses of corticosteroids (dexamethasone) was associated with a 28-day mortality reduction in patients with COVID-19 who required mechanical ventilation [6], our study did not demonstrate a statistically significant association between treatment with corticosteroids and reduced mortality in the population included. We believe that our results may have been influenced by the lack of standardization regarding the type, dose and timing of corticosteroid introduction.

With regard to the use of heparin, only $5.2 \%$ of the patients (8/154) were not exposed to this drug, which makes the comparison groups discrepant and may lead to an analysis bias. The low prevalence of individuals in the group not exposed to heparin may affect the conclusions drawn from the results found in our study. However, the analysis of hazard ratio (HR) contemplates this difference, which makes the results found in our cohort statistically acceptable. Among the 8 patients not exposed to heparin, $5 / 8$ did not receive the medication because they were severely thrombocytopenic and/or with active bleeding and $2 / 8$ evolved with cardio-respiratory arrest in the first $24 \mathrm{~h}$ of hospital admission, making it impossible to prescribe the medication. This may have influenced the results found, since patients not treated with heparin may have had a higher mortality due to present a more severe disease. However, one point that corroborates the potential benefit of heparin in patients hospitalized with COVID-19 was the low incidence of thromboembolic events $(1.29 \%-2 / 154)$ observed in our cohort, and possibly, this is a reflection of the massive use of prophylactic heparin in the patients included in the study. Although there was no active search for thromboembolism, several case series demonstrate higher rates of thromboembolic events in populations similar to ours $[22,26]$.

Despite of this work has been done to answer a question about HCQ in the setting of the COVID-19, it allowed us to take a picture of the clinical characteristics of our patients in the setting of this disease. We also could identify the main factors associated with mortality in our center.

In conclusion we confirmed that age and association of comorbid were predictive of poor prognosis in COVID19 and higher chance of mortality. However, heparin administration was associated with less mortality and hydroxychloroquine did not influence the mortality.

\section{Acknowledgements \\ Not applicable. \\ Authors' contributions \\ Conceptualization: ROC, JSN, JP; Data curation: ROC, JSN, APAC, MMB, MAPS, CEMT, AMS, RLH, CWS, BB, AAEK; Investigation: ROC; Methodology: COR, ROC, JP, MMB; Project administration: ROC, MMB; Validation \& Supervision: MMB, JP; Writing (original draft): ROC, LAPCL, JP; Writing (review \& editing): LAPCL, JP; All authors read and approved the manuscript.}

\section{Funding}

This study did not have funding.

Availability of data and materials

All data generated and analysed during this study are included in this published article. The raw data for this study are in the possession of the correspondence author and may be made fully available in the event of a request to the correspondence author via e-mail.

\section{Declarations}

Ethics approval and consent to participate

This study was approved by the local Ethic Committee (Hospital Guilherme Álvaro, Santos, SP, Brazil) in 2020, under the number 3448. Furthermore, the study was registered at the National Research Ethics Commission (CONEP number: 30538920.9.0000.0008) All procedures followed were in accordance with the ethical standards of the responsible committee on human experimentation (institutional and national) and with the Helsinki Declaration of 1975, as revised in 2008. Written informed consent was provided by patients or by their legal representatives.

\section{Consent for publication}

Not applicable.

\section{Competing interests}

The authors declare that they have no competing interests.

\section{Author details}

${ }^{1}$ Faculdade de Ciências Médicas de Santos - Centro Universitário Lusíada (FCMS, UNILUS), Santos, São Paulo, Brazil. ${ }^{2}$ Hospital Estadual Guilherme Álvaro 
(HGA), Santos, São Paulo, Brazil. ${ }^{3}$ Laboratory of Immunology and Histocompatibility (LIM-19), University of São Paulo (USP), São Paulo, Brazil. ${ }^{4}$ Department of Hematology, Hemotherapy \& Cell Therapy, University of São Paulo (USP), Av. Dr. Enéas de Carvalho Aguiar, 155 - 1st. Floor. Room 61, SP, São Paulo, Brazil. ${ }^{5}$ Laboratory of Medical Investigation in Pathogenesis and Directed Therapy in Onco-Immuno-Hematology (LIM-31), University of São Paulo (USP), Av. Dr. Enéas de Carvalho Aguiar, 155 - 1st. Floor. Room 61, São Paulo, SP, Brazil.

Received: 31 August 2021 Accepted: 31 January 2022

Published online: 04 February 2022

\section{References}

1. Wu Han health committee. Notice on the issuance of unexplained viral pneumonia [EB/OL]. 2020 http://wjw.wuhan.gov.cn/front/web/showD etail/2020010309017. Published January 3, 2020. Accessed February 8, 2020.

2. Johns Hopkins University \& Medicine Coronavirus Resource Center. https://coronavirus.jhu.edu/. Accessed 2 May 2021.

3. Gautret P, Lagier JC, Parola P, Hoang VT, Meddeb L, Mailhe M, et al. Hydroxychloroquine and azithromycin as a treatment of COVID-19: results of an open-label non-randomized clinical trial. Int J Antimicrob Agents. 2020;56(1):105949.

4. Ministério da Saúde, Brazil. Cloroquina poderá ser usada em casos graves do coronavírus. Brazil: Ministério da Saúde, 2020. https://www.gov.br/ cgu/pt-br/governo-aberto/noticias/2020/3/cloroquina-podera-serusada-em-casos-graves-do-coronavirus. Accessed 20 Mar 2020

5. Ministério da Saúde, Brazil. Ministério da Saúde divulga diretrizes para tratamento medicamentoso de pacientes. Brazil: Ministério da Saúde. 2020. https://www.saude.gov.br/noticias/agencia-saude/46919-minis terio-da-saude-divulga-diretrizes-para-tratamento-medicamentoso-depacientes. Accessed 20 May 2020.

6. Horby P, Mafham M, Linsell L, Bell JL, Staplin N, Emberson JR, The RECOVERY Collaborative Group. Effect of hydroxychloroquine in hospitalized patients with Covid-19. N Engl J Med. 2020;383(21):2030-40.

7. Simmering JE, Polgreen LA, Polgreen PM, Teske RE, Comellas AP, Carter $B L$. The cardiovascular effects of treatment with Hydroxychloroquine and Azithromycin. Pharmacotherapy. 2020;40(9):978-83.

8. Latreille $E$, Lee WL. Interactions of influenza and SARS-CoV-2 with the lung endothelium: similarities, differences, and implications for therapy. Viruses. 2021;13(2):161-86.

9. Cascella M, Rajnik M, Aleem A, Dulebohn SC, Napoli R. Features, evaluation and treatment of coronavirus (COVID-19). Stat Pearls. 2021; E-book (updated 17th. July 2021).

10. Hui DSC, Zumla A. Severe acute respiratory syndrome: historical, epidemiologic, and clinical features. Infect Dis Clin North Am. 2019;33(4):869-89.

11. Zhou F, Yu T, Du R, Fan G, Liu Y, Liu Z, et al. Clinical course and risk factors for mortality of adult inpatients with COVID-19 in Wuhan, China: a retrospective cohort study. The Lancet. 2020;395(10229):1054-62.

12. Wu Z, McGoogan JM. Characteristics of and important lessons from the coronavirus disease 2019 (COVID-19) Outbreak in China: summary of a report of 72314 cases from the Chinese Center for Disease Control and Prevention. JAMA. 2020;323(13):1239-42.

13. Ortiz-Prado E, Simbaña-Rivera K, Gómez-Barreno L, Rubio-Neira M Guaman LP, Kyriakidis NC, et al. Clinical, molecular, and epidemiological characterization of the SARS-CoV-2 virus and the Coronavirus Disease 2019 (COVID-19), a comprehensive literature review. Diagn Microbiol Infect Dis. 2020;98(1):115094.

14. Kadambari S, Klenerman P, Pollard AJ. Why the elderly appear to be more severely affected by COVID-19: the potential role of immunosenescence and CMV. Rev Med Virol. 2020. https://doi.org/10.1002/rmv.2144.

15. Moss P. The ancient and the new: is there an interaction between cytomegalovirus and SARS-CoV-2 infection? Immun Ageing. 2020;17(1):1-6.

16. Nicoli F, Solis-Soto MT, Paudel D, Marconi P, Gavioli R, Appay V, et al. Agerelated decline of de novo $T$ cell responsiveness as a cause of COVID-19 severity. Geroscience. 2020;42:1015-9.

17. Kim JA, Seong RK, Shin OS. Enhanced viral replication by cellular replicative senescence. Immune Netw. 2016;16:286-95.
18. Thakar J, Mohanty S, West AP, Joshi SR, Ueda I, Wilson J, et al. Agingdependent alterations in gene expression and a mitochondrial signature of responsiveness to human influenza vaccination. Aging. 2015;7:38-52.

19. Chen Y, Klein SL, Garibaldi BT, Li H, Wu C, Osevala NM, et al. Aging in COVID-19: vulnerability, immunity and intervention. Ageing Res Rev. $2021 ; 65: 10125$.

20. Cunha LL, Perazzio SF, Azzi J, Cravedi P, Riella LV. Remodeling of the immune response with aging: immunosenescence and its potential impact on COVID-19 immune response. Frontiers Immunol. 2020;11:1748.

21. Minami T, Iwata Y, Wada T. Renal complications in coronavirus disease 2019: a systematic review. Inflamm Regener. 2020;40(31):1-6.

22. Klok FA, Kruip MJHA, van der Meer NJM, Arbous MS, Gommers DAMPJ, Kant KM, et al. Incidence of thrombotic complications in critically ill ICU with COVID-19. Thromb Res. 2020;191:145-7.

23. Thachil J, Tang N, Gando S, Falanga A, Cattaneo M, Levi M, et al. ISTH interim guidance on recognition and management of coagulopathy in COVID-19. J Thromb Haemost. 2020;18(5):1023-6.

24. Paranjpe I, Fuster V, Lala A, Russak AJ, Glicksberg BS, Levin MA, et al. Association of treatment dose anticoagulation with in-hospital survival among hospitalized patients with COVID-19. J Am College Cardiol. 2020;76(1):122-4

25. Buijsers B, Yanginhar C, Maciej-Hulme ML, de Mast Q, van der Vlag J. Beneficial non-anticoagulant mechanism underlying heparin treatment of COVID-19 patients. Lancet. 2020;59:102969.

26. Middeldorp S, Coppens M, van Haaps TF, Foppen M, Vlaar AP, Müller MCA et al. Incidence of venous thromboembolism in hospitalized patients with COVID-19. J Thromb Haemost. 2020;18(8):1995-2002.

\section{Publisher's Note}

Springer Nature remains neutral with regard to jurisdictional claims in published maps and institutional affiliations.

Ready to submit your research? Choose BMC and benefit from

- fast, convenient online submission

- thorough peer review by experienced researchers in your field

- rapid publication on acceptance

- support for research data, including large and complex data types

- gold Open Access which fosters wider collaboration and increased citations

- maximum visibility for your research: over $100 \mathrm{M}$ website views per year

At BMC, research is always in progress.

Learn more biomedcentral.com/submissions 